\title{
The Possibilities for Mitigating Negative Effects of Transport
}

\author{
V. Adamec, J. Jedlička*, R. Ličbinský \\ Division of Transport Infrastructure and Environment, Transport Research Centre, Brno, Czech Republic \\ *Corresponding author: jiri.jedlicka@cdv.cz
}

DOI: $10.2478 / \mathrm{v} 10158-011-0012-\mathrm{x}$

\begin{abstract}
The success of the correct execution of designed measures depends on our succeeding in reducing the negative influences of transport on health and the environment; however, to eliminate these negative effects it is almost always necessary to take more measures. In this case we speak of a set of measures which are inter-connected, and their efficiency is thereby enhanced. As an example, it is possible to mention the increase of the positive influence of a new service of urban public transport on the reduction of car transport, together with the building of an park and ride facilities in a suitable area on the public transport service route. From the design stage of the measures to their implementation it often takes a long time, therefore the complex of the measures should always be designed by a team of experts who are capable of judging the efficiency of various alternatives and subsequently design an optimum solution.
\end{abstract}

KEY WORDS: transport, mitigation, measures, impact on the environment.

\section{INTRODUCTION}

In the field of influences of transport on health and the environment, a primary task is to take such measures which would eliminate, or at least mitigate, negative effects. It is a task not only for the government, but for regions, towns, and communities as well. It is necessary to realize that the negative influences of transport are a result of the behaviour of people, and their everyday decision-making process whether to go on a journey, where to go, which means of transport to choose, and which route to follow. A range of factors has an influence on this decision-making: mainly social-economic characteristics of the population and their relation to the environment and the properties of the available transport systems (travelling time, costs, comfort and safety of the individual modes of transport). This is the basis for another goal of the measures - to influence the transport behaviour of the population for the benefit of the most environmentally friendly modes of transport.

The measures could be divided to supply measures - e.g. building of the new infrastructure with safety and environmental elements, higher quality means of transport, and management of transport systems - and demand measures, which should lead to the limitation of demand for harmful modes of transport.

The demand measures include the management of mobility, higher parking fees, limited car traffic in the city centres, closer of origins and destinations within transport planning, etc. The measures outside of the above mentioned are the so-called soft measures, which include 
an integration of public in the decision-making about transport projects, environmental education of the population, "eco-driving", etc.

Table 1: Scheme of the measures classification.

\begin{tabular}{|c|c|c|}
\hline \multirow{11}{*}{ Measures on roads } & \multirow{5}{*}{ Anti-Noise protection measures } & \multirow{2}{*}{$\begin{array}{l}\text { - anti-noise walls } \\
\text { - } \text { constructions along roads (houses, } \\
\text { garages) preventing noise propagation }\end{array}$} \\
\hline & & \\
\hline & & - natural embankments \\
\hline & & - green strips \\
\hline & & - low-noise road surfaces \\
\hline & $\begin{array}{l}\text { Protection against contamination } \\
\text { of waters and soil }\end{array}$ & - sedimentation tanks \\
\hline & \multirow{5}{*}{ Measures for fauna protection } & - ecoducts ("overpasses") \\
\hline & & - adjustments of road crossing watercourses \\
\hline & & - dry tunnels and bridges \\
\hline & & - culverts \\
\hline & & - guide fences \\
\hline \multirow{6}{*}{$\begin{array}{l}\text { Measures } \\
\text { on vehicles }\end{array}$} & \multirow{4}{*}{ Devices burnt fuel treatment } & - 3-way controlled catalytic converters \\
\hline & & - oxidation catalytic converters \\
\hline & & - recirculation of exhaust gases \\
\hline & & - particulate filter \\
\hline & \multirow[b]{2}{*}{ Reduction of noise of vehicles } & - noise reduction from drives \\
\hline & & $\begin{array}{l}\text { - noise reduction from sucking and exhaust } \\
\text { devices }\end{array}$ \\
\hline \multirow{5}{*}{$\begin{array}{l}\text { Legislative } \\
\text { measures }\end{array}$} & Emission limits & $\begin{array}{l}\text { - introduction of European norms EURO 1- } \\
5 \text { for new vehicles }\end{array}$ \\
\hline & Noise limits & $\begin{array}{l}\text { - introduction of European standards in the } \\
\text { new vehicles }\end{array}$ \\
\hline & \multirow{3}{*}{ Economic and tax tools } & $\begin{array}{l}\text { - charging for use of the transport } \\
\text { infrastructure }\end{array}$ \\
\hline & & $\begin{array}{l}\text { - discounts for road tax for the "more } \\
\text { environmentally friendly" vehicles }\end{array}$ \\
\hline & & - excise tax on fuel \\
\hline \multirow{2}{*}{\multicolumn{2}{|c|}{ Improvement of fuel quality }} & - ban on leaded petrol \\
\hline & & $\begin{array}{l}\text { - reduction of content of sulphur in petrol } \\
\text { and diesel }\end{array}$ \\
\hline \multirow{6}{*}{$\begin{array}{l}\text { Support of public } \\
\text { and multi-modal } \\
\text { transport }\end{array}$} & \multirow{3}{*}{$\begin{array}{l}\text { Increase of attraction } \\
\text { of public transport }\end{array}$} & $\begin{array}{lll}\text { - introduction of integrated transport } \\
\text { system (IDS) }\end{array}$ \\
\hline & & - increase of the comfort for passengers \\
\hline & & - preference of public transport \\
\hline & \multirow{3}{*}{ Support of the combined transport } & - introduction of the system "Park and Ride" \\
\hline & & $\begin{array}{l}\text { - introduction of the system "Bike and } \\
\text { Ride" }\end{array}$ \\
\hline & & - systems of the combined freight trasnport \\
\hline \multicolumn{3}{|l|}{ Mobility management } \\
\hline \multicolumn{3}{|c|}{ Environmental education, education, and enlightenment } \\
\hline \multicolumn{3}{|c|}{ Integration of public in transport projects } \\
\hline \multicolumn{3}{|l|}{ Eco-driving } \\
\hline \multicolumn{3}{|l|}{ Land use planning } \\
\hline
\end{tabular}




\section{MEASURES ON ROADS}

The measures on the roads are very varied, because they concern various effects of the transport infrastructure on the health of population and the environment. The road represents a source of noise from vehicle traffic, causes pollution of the surrounding environment through drainage water, and last, but not least, it works as a barrier effect, which leads to the restriction of the movement of wild animals.

\subsection{Anti-noise measures}

The anti-noise screens are installed in order to protect the health of the population from the effects of noise. The aim is to reduce noise from road transport to limits specified in hygienic regulations. The following types of the walls are recognized: anti-noise walls, buildings (houses, garages), earth embankments (natural or artificial), and strips of vegetation (Durčanská et al., 2002). Well designed barriers brings on average a reduction of noise of approximately 4 and more $\mathrm{dB}(\mathrm{A})$, depending on the conditions (geometry) of the traffic noise propagation. It is generally accepted that the required efficiency is assured if the source of noise is not visible from any place of the receiver, then the energy only moves through diffraction or reflection of sound waves. In order to assure the maximum acoustic effectiveness, the anti-noise barriers should be located as close as possible to the source of the noise. Furthermore, it is desirable that the character of the barriers eliminate the undesirable reflection of the sound and that the barrier blend in with the environment, if possible. Attention should be paid to the edge of the barrier as well, so that vehicles on the road are not threatened by a sudden change in the dynamics of the wind streaming (Haberl, J. et al., 2005).

An urban solution with the use of barrier houses, multi-storey garages, and other screening "objects", is often used. The earth embankments are, compared to barriers, more demanding on the land use, and, due to their higher distance from the top of the hill to the road, they have lower reducing effects as well. However, planting vegetation at the top of the embankment can influence these effects in a very positive way. The disadvantage of the earth embankment is their demanding land use. The strips of vegetation have a bioclimatic, hygienic, architectonic and aesthetic function. The spread of noise in the vegetation gets absorbed thanks to the absorptiveness of tree leaves and the Earth's surface, and the multiple dispersal on trunks and branches. The vegetation (not only) along roads influences in a positive way the quality of air and health of people as well, because it captures dust particles and transforms the carbon dioxide into oxygen via photosynthetic processes. Because the perception of noise is rather individual and depends on actual mental condition of a person, the vegetation can considerably reduce the harmful effects on the health of people, because the noise objectively does not change.

\subsection{The low-noise road pavements}

Low-noise road pavements play an important role within communities and cities, in which the anti-noise barriers cannot be constructed due to insufficient space, the necessity to provide unobstructed access to roads, or due to aesthetic reasons. Noise reduction through road pavement represents a real measure at the source. Each road pavement is, during its use, deteriorating due to impairment caused by vehicles, which can lead to an increase of noise by up to $3 \mathrm{~dB}$. The extensive European research project SILENCE has, among others, dealt with the issue of noise between tyres and the road pavement (Bendtsen \& Schmidt, 2006). On the basis of experimental measurement of noise of the surfaces by the method CPX (Close Proximity Method), the project designed an acoustic evaluation of road pavement 
through three degrees of damage: good condition $(+0 \mathrm{~dB})$, favourable condition $(+1 \mathrm{~dB})$ and unfavourable condition ( $+2 \mathrm{~dB}$ and more).

Due to insufficiently clear evaluation of the noise levels of the individual surfaces, the five classes of noise of road pavement were defined as well: very noisy (reference pavement $+3 \mathrm{~dB}$ and more), noisy (reference pavement +1 up to $2 \mathrm{~dB}$ ), normal (reference pavement), silent (reference pavement -1 up to $2 \mathrm{~dB}$ ) and noise reducing (reference pavement $-3 \mathrm{~dB}$ and more). For the reference pavement bituminous concrete is considered with a maximum aggregate size of $11 \mathrm{~mm}$ up to $12 \mathrm{~mm}$ or road pavement with a similarly fine surface structure.

\subsection{The protection from contamination of water and soil}

For the protection from potential contamination of water and soil, sedimentation tanks are used into which drainage lead draining the rain water out of the surface of road pavement. The drained water is gravitationally removed from suspended particles heavier than water, and from liquid particles lighter than water. During the sedimentation and retention of the water in the tank, partial degradation of the organic matter could also occur owing to the activity of microorganisms. The process of biological cleaning of drainage water, drained from the road surface, is also used in retention tanks. The sedimentation and retention tanks are in the Czech Republic found mainly alongside motorways and dual carriageways with high traffic volume.

\subsection{Ecoducts and passages for fauna}

Ecoducts and passages for fauna are used for mitigating the effects of the fragmentation of the localities by the transport infrastructure. There are methodologies produced at the national (Anděl et al., 2005) and international (Iuell et al., 2003) levels for the construction of ecoducts and passages. With the construction of new roads it is very important to take into account the already existing transport networks or other barriers. In the countries of Western Europe a principle is used that in the case of multi-modal transport corridors it is suitable to locate individual routes as close to each other as possible.

The design, density and location of the passages for fauna are very important as well. The passages should be designed in cooperation of the designer with an environmental expert, and should be focused on one or more specific species. The total migration significance of the area and other barriers in the surroundings (e.g. the above-mentioned original roads) have to be taken into consideration when deciding on the location of the passage. It is suitable to locate the passage at a place where parallel transport networks come close to each other. The dimensions of the passage (bridge, culvert) as well as the character of the underpass should correspond with the size of the species. An underpass with foreign elements is unsuitable: paving, concrete, sharp stones, handrail, etc. Planting of the underpass with the original vegetation and bushes is suitable, not only in terms of passability, but also in terms of monitoring passing animals as well. The specific solution is the so-called overpasses, which are constructions designed for the migration of animals over roads. Owing to their financial cost, they are recommended only in really justified cases, after negotiation with bodies for the protection of nature. In developed countries overpasses are common solution, they are mostly constructed in a way that they are narrowing down towards the centre of the road and they get wider towards the edges (Iuell et al., 2003). It is suitable to build overpasses in the localities where the road runs deeper in the ground and the surrounding terrain is elevated. They are usually pointless on flat terrain.

The fencing for the whole length of the road is most commonly used for prevention of accidents between animals and vehicles. The continuous fencing on the one hand reduces 
animal fatalities, but, on the other hand, increases the barrier effect of the given road. Currently fences in the shape of "V" are more recommended in the surroundings of the passages, which guide the animals through the passage. In the case of fencing for along the whole length of road, it is more suitable to locate the fences between road and the edge of a forest. If the fence runs along the edge of a forest, or even in a forest, it is often overlooked by animals, so it works as a trap. Some sections of older motorways make almost insurmountable barriers, because, at the time of their construction, the aspect of fragmentation was not really taken into consideration. The most common barriers in the case of old bridges are "cascade" layout of the watercourse, too small passages, low height, absence of vegetation, inconvenient underpass, etc. In these cases the extension of unsuitable bridges and adjustment of their underpass should be included in the plans of a reconstruction of the motorway and road network.

\section{MEASURES ON VEHICLES}

In this chapter not only technical, but also legislative measures are included as well emission limits, which directly concern the issue of vehicles. Emission limits are directly related to technical measures, because new stricter limits directly force the car producer to further technological improvements.

\subsection{Emission limits and renewal of vehicle fleet}

A very significant contribution to the reduction of effects of transport on the health of the population is the renewal of vehicle fleet. The decommissioned vehicles are mostly older types, with a non-functioning catalytic converter, or without any catalytic converter, and tend are usually replaced by new vehicles which meet stricter emission standards. The Czech Republic uses the system of emission limits EURO 1-5 for road vehicles, which is used in all countries of the EU. Since 1 October 2006 the registration, sale, putting into operation, and use of new heavy vehicles with an emission limit lower than EURO 4 are not allowed, with the exception of vehicles intended for export to developing countries or spare motors for the vehicles in operation. The ban on registration of passenger and light freight vehicles with the emission limit lower than EURO 4 has been in force since $1^{\text {st }}$ January 2006. The new, stricter emission limits EURO 5 have been effective in all EU countries for new vehicles since $1^{\text {st }}$ January 2009. The limits EURO 5 mostly reduce the emission limits of particulate matter - five times more compared to the EURO 4 standard. This limit can be met by car producers only with the installation of effective micro filters. More detailed circumstances about the legislation referring to emissions from transport are mentioned in the respective chapter.

Table 2: Emission limits EURO for passenger cars with petrol engines (Directive 70/220/EEC).

\begin{tabular}{|c|c|c|c|c|c|c|}
\hline Limit & Year & $\begin{array}{c}\mathrm{CO} \\
\left(\mathrm{g} . \mathrm{km}^{-1}\right)\end{array}$ & $\begin{array}{c}\mathrm{HC}+\mathrm{NOx} \\
\left(\mathrm{g} . \mathrm{km}^{-1}\right)\end{array}$ & $\begin{array}{c}\mathrm{HC} \\
\left(\mathrm{g} . \mathrm{km}^{-1}\right)\end{array}$ & $\begin{array}{c}\mathrm{NOx} \\
\left(\mathrm{g} . \mathrm{km}^{-1}\right)\end{array}$ & $\begin{array}{c}\text { PM } \\
\left(\text { g. } \mathrm{km}^{-1}\right)\end{array}$ \\
\hline EURO 1 & 1992 & 2.72 & 0.97 & - & - & - \\
\hline EURO 2 & 1996 & 2.2 & 0.5 & - & - & - \\
\hline EURO 3 & 2000 & 2.30 & - & 0.2 & 0.15 & - \\
\hline EURO 4 & 2005 & 1 & - & 0.1 & 0.08 & - \\
\hline EURO 5 & 2009 & 1 & - & 0.1 & 0.06 & 0.005 \\
\hline
\end{tabular}


Table 3: Emission limits EURO for passenger cars with diesel engines(Directive 70/220/EEC).

\begin{tabular}{|c|c|c|c|c|c|c|}
\hline Limit & Year & $\begin{array}{c}\mathrm{CO} \\
\left(\mathrm{g} . \mathrm{km}^{-1}\right)\end{array}$ & $\begin{array}{c}\mathrm{HC}+\mathrm{NOx} \\
\left(\mathrm{g} . \mathrm{km}^{-1}\right)\end{array}$ & $\begin{array}{c}\mathrm{HC} \\
\left(\mathrm{g} . \mathrm{km}^{-1}\right)\end{array}$ & $\begin{array}{c}\mathrm{NOx} \\
\left(\mathrm{g} . \mathrm{km}^{-1}\right)\end{array}$ & $\begin{array}{c}\mathrm{PM} \\
\left(\mathrm{g} . \mathrm{km}^{-1}\right)\end{array}$ \\
\hline EURO 1 & 1992 & 2.72 & 0.97 & - & & 0.14 \\
\hline EURO 2 & 1996 & 1 & 0.7 & - & & 0.08 \\
\hline EURO 3 & 2000 & 0.64 & 0.56 & - & 0.5 & 0.05 \\
\hline EURO 4 & 2005 & 0.5 & 0.30 & - & 0.25 & 0.025 \\
\hline EURO 5 & 2009 & 0.5 & 0.23 & - & 0.18 & 0.005 \\
\hline
\end{tabular}

Table 4: Emission limits EURO for heavy vehicles with diesel engines (Directive 70/220/EEC).

\begin{tabular}{|c|c|c|c|c|c|}
\hline Limit & Year & $\begin{array}{c}\mathrm{CO} \\
\left(\mathrm{g} . \mathrm{kWh}^{-1}\right)\end{array}$ & $\begin{array}{c}\mathrm{HC} \\
\left(\mathrm{g} . \mathrm{kWh}^{-1}\right)\end{array}$ & $\begin{array}{c}\mathrm{NOx} \\
\left(\mathrm{g} . \mathrm{kWh}^{-1}\right)\end{array}$ & $\begin{array}{c}\mathrm{PM} \\
\left(\mathrm{g} . \mathrm{kWh}^{-1}\right)\end{array}$ \\
\hline EURO I & 1992 & 4.5 & 1.1 & 8 & 0.36 \\
\hline EURO II & 1996 & 4 & 1.1 & 7 & 0.25 \\
& 1998 & 4 & 1.1 & 7 & 0.15 \\
\hline EURO III & 2000 & 2.1 & 0.66 & 5 & 0.1 \\
\hline EURO IV & 2005 & 1.5 & 0.46 & 3.5 & 0.02 \\
\hline EURO V & 2008 & 1.5 & 0.46 & 2 & 0.02 \\
\hline
\end{tabular}

\subsection{Emission reduction devices}

The reduction of pollutant emissions by vehicles is reached through an improvement of the combustion engine and mainly devices for the adjustment of burnt gases, catalytic converters. The first vehicles with catalytic converters started to appear on the road in 1975. Petrol vehicles are currently equipped with three-way catalytic converters, containing an oxidation and reduction part. Diesel vehicles are equipped only with an oxidation catalytic converter. The producers of heavy vehicles were forced, by a strict reduction of the emission limits of nitrogen oxides (NOx) in the burnt gases, to develop new devices for the adjustment of burnt gases. There are currently two types of heavy vehicles on the market, those with the system of adjustment of burnt gases EGR- recirculation of the exhaust gases, or SCRselective catalytic reduction, which can both meet the emission limits EURO 5.

The technology EURO 5 uses an additive with the name AdBlue (pure colourless liquid composed of $32.5 \%$ Aqueous Urea Solution), which is injected into exhaust gases before they go through the catalytic converter SCR. In the catalytic converter nitrogen oxides are transformed into nitrogen and water vapour. The advantage of the method using SCR is the fact that it could be modified in a way that would make it compatible with the requirements EURO 5 and EURO 6 as well. For example, in the case of motors EURO 5, more of the additive AdBlue is injected in order to reduce the content of nitrogen oxides. In case of standard EURO 4, the quantity of the additive is approximately $3-4 \%$ of the fuel quantity, and at the standard EURO 5, approximately 5-7\%. EGR is a system of recirculation of the burnt gases.

In order to reach the lower temperature of burning, which reduces the emissions of nitrogen oxides to the required level, the regulated quantity of the exhaust gases, up to $18 \%$ of EURO 4 and $25 \%$ of EURO 5, cools down in the EGR cooler and returns back to the motor. The emissions of particulate matter (PM) is reduced by the high pressured 
injected system. The current situation and developing trend in the equipment of vehicles with catalytic converters in the Czech Republic is apparent from the following Table.

Table 5: Number of vehicles per type and emission category in 2009 (Adamec et al, 2010).

\begin{tabular}{|l|c|c|c|c|c|}
\hline Type of vehicle & EURO I & EURO II & EURO III & EURO IV & EURO V \\
\hline Passenger cars and LDV & 488.4 & 1166.1 & 1151.4 & 842.0 & 179.2 \\
\hline Heavy vehicles & 11.9 & 14.2 & 41.1 & 31.1 & 16.0 \\
\hline Buses & 1.39 & 2.14 & 5.50 & 2.81 & 2.25 \\
\hline Total & 501.66 & 1182.42 & 1198.02 & 875.86 & 197.47 \\
\hline
\end{tabular}

The classification of vehicles according to their equipment with catalytic converters comes from the statistics of the Central register of vehicles. In relation to the speed of the renewal of vehicle fleet, the number of vehicles equipped with catalytic converters is increasing. But the vehicles with catalytic converters drive considerably more kilometres than older vehicles without catalytic converters.

Therefore, in traffic, considerably more vehicles equipped with the catalytic converters are represented - even up to $95 \%$.

\subsection{Reduction of noise of vehicles}

The possibilities for noise reduction can be divided into the reduction of noise of the fuel unit, reduction of the sucking noise and exhaust pipe noise, and the noise reduction of the tyre/road pavement (the so-called rolling noise).

The rolling noise comes from the friction of tyres on road pavement,and depends on the speed of driving (Hensher \& Button, 2003). In the past it played a less significant role when considering the high limit values of external noise of motor vehicles, as it was exceeded by the noise from the drive unit. The noise of the drive unit depends on the revolutions of the engine and the load of the engine, but not on the speed of driving.

The gradual limitation of the level of noise from the sucking and exhaust devices led to a decrease in the values of the external noise of motor vehicles. Currently, the noise from the drive unit is only dominant at starts, when accelerating, or when braking by the engine. At higher speeds, the rolling noise of the tyres on the road pavement starts to predominate in the acoustic emissions from the vehicle. The rolling noise depends on the tyre, to be more precise, on the production of better surface texture (thread) of the tyre and on the development of low-noise surfaces of road pavements. The road pavement, mainly surface texture, influences the noise of the vehicle at the place of its origin and has an influence on its propagation.

\section{IMPROVEMENT OF FUEL QUALITY}

A reduction of emissions of certain pollutants is also assured by the increasing qualitative requirements on car fuels. In 2001 the distribution of leaded petrol finished in the Czech Republic. Since 2000 the emphasis has also been placed on the reduction of sulphur content and other pollutants in the petrol and diesel. 
At present, fuel with a very low sulphur content is distributed in the Czech Republic, mostly meeting the requirements for sulphur content from 2009. The maximum permissible contents of individual pollutants in petrol and diesel are mentioned in Table 6 .

Table 6: Requirements on the content of pollutants in car fuels.

\begin{tabular}{|l|c|c|}
\hline Automobile petrol & since 1 January 2000* & since 1 January 2005 \\
\hline max. sulphur content [mg. kg ${ }^{-1}$ ] & 150 & $50(10)^{* *}$ \\
\hline max. benzene content [\% volume] & 1.0 & 1.0 \\
\hline max. content of aromatics [\% volume] & 42 & 35 \\
\hline max. content of olefins [\% volume] & 18 & 18 \\
\hline max. content of oxygen [\% weight] & 2.7 & 2.7 \\
\hline max. content of lead [mg. ${ }^{-1}$ ] & 13 & 13 \\
\hline \multicolumn{2}{|c|}{ Motor diesel } \\
\hline max. sulphur content [mg. $\mathrm{kg}^{-1}$ ] & 350 & $50(10)^{* *}$ \\
\hline max. content PAH [\% volume] & 11 & 11 \\
\hline min. cetane number & 51 & 51 \\
\hline
\end{tabular}

* values have become effective in Czech Republic since $1^{\text {st }}$ January 2003, on the basis of the Announcement Ministry of Work and Trade No. 227/2001.

** the values mentioned in the brackets came into force on $1^{\text {st }}$ January 2009.

Another important measure is the gasification of vehicle fleet of public transport operators. Older vehicles are replaced with newer compressed natural gas (CNG) vehicles, which emit several-fold lower amount of emissions of pollutants than diesel buses.

\section{THE SUPPORT OF ENVIRONMENTALLY FRIENDLY MODES OF TRANSPORT}

One of the important tools to mitigate negative influences of transport is a change in modal split to more ecologically beneficial modes of transport. These modes of transport predominantly include rail, public, and non-motorised transport. Public transport should be sufficiently attractive in order to motivate the population to use this transport mode more often. There are a range of possibilities to improve attractiveness of public transport, however not all of them are always suitable for specific situations. It is necessary to carefully combine these methods under local conditions.

\subsection{Increasing attractiveness of public transport}

a) Introduction of integrated transport systems (IDS)

Integrated transport provides transport services of an area via public transport with the use of individual road transport operators, or road transport operators together with operators in another transport mode, or by an operator operating more transport modes. Therefore, the individual operators and transport modes do not compete with each other in IDS, they try to cooperate in order to gain new customers from the group of users of passenger cars.

The unified rules for the operation of IDS are not provided, and they differ from case to case, but it is always based on the voluntary agreement of the operators. Usually, this type method includes enforcement of a unified tariff policy (on one travel ticket is possible to travel on the whole network with various operators), mutual interconnection 
of the timetables of the integrated carriers and the creation of the new change hubs, elimination of parallel services of more carriers, and creation of a timetable for services going in a regular intervals. In the Czech operators, 13 IDS are currently being operated with different levels of integration. Prague, Ostrava, and South Moravian region are among the biggest and most elaborated systems.

\section{b) Increase in comfort for passengers}

In order to increase the comfort during travel, modern, low-floor vehicles, allowing for easier entry and exit of passengers have been put into operation; these are also suitable for the transport of the impaired and mothers with prams. A necessary procedure for urban public transport is the equipping of quality information systems for passengers. The construction or modernization of change terminals is being carried out to facilitate the easier movement of passengers, with the introduction of edge-edge change system (services leave from different sides of one platform so passengers do not have to go to other platforms through underpasses, overpasses, or even directly across the road), and sufficient maintenance providing higher comfort of travel. Other elements enhancing the comfort of travelling by public transport are, e.g. air-conditioning, cleanness, and interior design, etc.

\section{c) Preference of public transport vehicles}

The vehicles of public transport are slowed down by automobile transport, mainly in cities. One of the assumptions for an attractive public transport is the sufficient travel speed. Therefore, preferential measures are being introduced, e.g. the introduction of designed lanes for buses and trolley buses in busy locations, or the preference the urban public transport vehicles at traffic signalled junctions.

\subsection{Introduction of systems "Park and Ride" and "Bike and Ride"}

\section{a) Park and Ride}

The system "Park and Ride" (P\&R) means that the driver travels a part of his journey by car from the place of residence to a car park, where they change to a public transport vehicle, in which they continue their destination. This system should be combined with higher rates of parking fees in localities which are to be calmed (mainly in city centres), or with the introduction of fees charged for entrance to these localities. The necessary assumption for the realization of this system is the construction of parking houses and $P \& R$ car parks. In towns it is recommended to build P\&R car parks in outskirts, at places of important hubs of urban public transport. Outside urban areas it is recommended to build such car parks mainly at the main rail stops leading to a central town of a given region. The parking policy should put off drivers from entering city centres, e.g. by increasing fees, and also motivate them to make multi-modal trips, i.e. partly by car and partly by urban public transport.

For the installation of $\mathrm{P} \& \mathrm{R}$ it is necessary to ensure clear directing road signs (signs for the car park, with the letters "P\&R") and ensure more services of urban public transport at the localities in question. The payment for parking should be reflected in the price of the fare. In order to ensure the maximum use of the car parks, locations should be chosen on the basis of socio-economic research of transport behaviour and demand for P\&R, and a subsequent modelling of wider transport relationships of the given area (LeeGosselin \& Doherty, 2005). 
The psychology of car drivers, who are now used to driving all the way to their destination, represents a certain obstacle in the implementation (efficiency) of this measure. It will probably take a long time before at least some people will willingly leave their vehicles, even though in car parks with surveillance, and continue by public transport. The drivers should have financial motivation for this measure, e.g. the parking ticket price should be incorporated into the price of the ticket for the urban public transport.

\section{b) Bike and Ride}

The system "Bike and Ride" (B\&R) is similar to the system "P\&R", only instead of a car a bicycle is used, from the origin of the trip (place of residence) to a car park, or to a building for the storage of bicycles. After parking the bicycle the cyclist exchanges bike saddle for a public transport seat and continues until completing the trip. Whereas car drivers are usually not prevented from parking their car in a suitable place and continuing to their destination by public transport, cyclists usually have no opportunity to leave their bicycle without supervision at urban public transport stops. This system should allow for the storage and safe parking of bicycles, mainly at the end stations and important hubs of urban public transport. The existing parking areas or public places under the ownership of the city should be preferred. The buildings for the storage and parking of the bicycles could have, e.g. a form of a "cage", or special stands, with a fence and lockable doors, which can be opened by a card or coin. The measures should also make bicycle transport more attractive for people who are less physically capable, and who would like to use a bicycle for commuting to work, but for whom the completion of the whole route, from the place of residence to the workplace would be a strenuous physical activity on bicycle. Another possibility is the combination of the system $B \& R$ and $P \& R$ in areas where these options are possible together. The bicycle storage should, in this case, be located directly at the car park.

\subsection{Systems of freight combined transport}

Not only the transport of people, but also freight transport can be executed in a multi-modally. In terms of mitigating the effects on the health of the population, goods should be transported on rail at the highest possible degree. Water transport is considered "environmentally friendly" transport as well, but this is debatable considering the negative effects on water ecosystems. In this perspective, road transport is considered to be the least environmentally friendly. However, rail transport is not able to handle the total transport of goods to its destination, i.e. "from door to door". Therefore, the transfer of all transport of goods from road to railway is unrealistic.

However, a part of the transported volume of selected commodities is possible to be transferred to railways, with the help of building logistics centres at important railway stations. Places for the storage of goods should be built, and from there goods are sent on freight vehicles to target destinations. This combined option for freight transport should then be offered to fright operators, who are particularly interested in these services for foreign transport. The areas for the placement of logistics centres have to have a direct connection to the main railway routes.

The access for heavy vehicles should run outside of the built-up areas. Equipping the station with a rail siding is beneficial. The building of logistic centres can be one of the ways how to revitalize unused premises, i.e. "brownfields" (these tend to be rail-sided, there are storage and loading spaces, etc.). Each proposed solution for logistics centres should be evaluated from the freight transport perspective. 


\subsection{Bicycle transport support}

The aim, of this measure is to build a compact network of cycle paths which guarantees a relatively quick and safe connection of important origins and destinations, not only recreational ones, but predominantly from places of residence to workplaces. The designing of specific cycle paths should be preceded by a production of a general development plan (or a study) of cycle trail network.

The general development plan determines the proportional rate of investments in bicycle infrastructure considering the needs of cyclists. The designed and gradually implemented network of cycle paths should meet these basic principles: coherence of the network, interconnection of the origins and destinations, and the attractiveness of the paths in terms of length, safety, and general comprehensiveness. Within the road arrangement a suitable cycle path is designed and its suitable alignment is recommended. The cycle paths should be conveniently separated from motorised transport: e.g. with an edge line, central resere (green), kerb, fence, or safety barrier (Bartoš, 2006). It is suitable to use the road alignment along watercourses, and along the so called "greenways" in the vegetation. In the cities the bicycle infrastructure should be completed with buildings for storage and safe parking of bicycles (see Chapter 5.2 - "Bike and Ride").

\section{MOBILITY MANAGEMENT}

Mobility management is an approach focused primarily on demand in passenger and freight transport, and therefore is sometimes translated into Czech as transport demand management. It tries to change the attitude and behaviour of the population towards sustainable types of transport.

The tools for the management of mobility are based on informing, communication, organization, and coordination. Mobility management is different from traffic system management, which is an approach focused on the supply, which tries to optimize the capacities of traffic corridors with telematics methods, pricing systems, etc. However, some tools could be similar in both approaches; management of traffic system is more focused on the solution of the final approach ("end of pipe approach"), whereas mobility management precedes this approach, and is therefore more preventive and systemic. For mobility management the influence of human choice on traffic is especially important before people decide how, where, and whether they travel.

The establishment of mobility management responded to the need of such approaches in the solution of a burning issue of ever-growing demand for mobility, which simply does not rely on building of new roads or the introduction of advanced technologies. Apart from these "hard" measures, there is an urgent need for more "soft" measures which will provide a wide range of services satisfying the needs of users and influencing them to change their transport habits towards sustainable transport. Management mobility specifically consists of providing information and consultation including, e.g. cycle maps, freight transport maps, itineraries of organizations, maps of the availability of schools, companies and other organizations, information on the possibility to change public transport, timetables, and other information.

It further deals with consultancy activities in the sense of analysis of availability and designing of alternatives and recommendations, such as transport plans of organizations or a comparison of different transport modes in terms of travel time, costs, and effects on the environment. 


\section{ENVIRONMENTAL EDUCATION AND AWARENESS}

Changes to the transport system which should mitigate the effects on health and the environment, are not possible without the wide support of the public. Furthermore, these changes have to be designed at a high professional level and, therefore, the transport experts have to be educated appropriately and motivated in the field of the environment. Last, but not least, the political support for the projects which would lead to a reduction of negative impact on the environment is necessary. These three groups - the public, experts, and political representation - are crucial for the desired changes.

The environmental education has to start already with children, in order to have a chance for greater success. The environmental education has already been established as a subject in primary schools. Unfortunately, it is still rather a marginal subject and often its content is still inadequate for the matter which it concerns. This is caused by, among other factors, the fact that there is no sufficient education of the environmental education at education faculties, where the so-called environmental minimum has not yet been fixed.

This is necessary to ensure that the graduates of the faculties master the rudiments of the environmental education. As far as the integration in education of the issue of transport, health, and the environment is concerned, the situation is even less favourable. An example of the integration of the environmental and human aspects of transport in education could be the Methodical instruction "Transport and the environment" intended for primary and secondary schools, published by the Club for Environmental Education, on which compilation the employees of Centrum dopravního výzkumu (CDV) participated. Outside of the field of education, the highest attention is paid to environmental education from the perspective of non-governmental, non-profit organizations (NGO). However, they are unable to cover all involved population within the whole issue.

From the research carried out with primary schools' students it was discovered that the ability to act in an environmentally friendly manner, according to the knowledge gained through environmental awareness, was almost entirely missing. There is a struggle between old and new values for students, whereas environmental values in the conflict with competitive ones are clearly losing.

The transport behaviour is motivated by speed, comfort, and the attractiveness of transport, not by the pursuit of sustainable transport and meeting the fundamental principles of sustainable development.

\section{THE INVOLVEMENT OF THE PUBLIC}

It is necessary that the public is involved in the process of transport planning and decisionmaking. In this respect, the transport planning field has limited historical experience. The planning processes are, in many cases, reserved mainly for transport experts, politicians, and state administration officials. This is particular the case of countries with a short duration of democracy, among which the Czech Republic is rated.

Decision-making in the so-called young democracies is often characterized by technical rationality, decision-making directed "from above", and is often linked to lengthy bureaucratic procedures. This model of decision-making is possible to be called democratic elitism. The key decisions tend to be made by a small group of oficials and politicians, and if some participative techniques are used in the decision-making, they are chosen and executed in a way that guarantees the support of the official form of the project and contradictory opinions were eliminated. 
The opposite of democratic elitism is a model called participative democracy. An important characteristics of this model is the necessity for direct involvement of the public in the decision-making. In this case, the public has a direct influence on the final form of the project, because the differences between the expert and layman opinions are minimized. The decision-making is based on the availability, cooperation, negotiation, and interactivity. From the many examples in practice it is apparent that the thoroughly planned and realized participation of the public could contribute considerably to decisions of higher quality. The early integration of the public in the evaluation of transport needs and the alternatives of transport decisions leads to the fact that the population accepts the decisions "for their own benefit", tolerates them more easily, and accepts the negatives of the implemented transport projects better as well.

According to the law, citizens have the possibility to get involved in the decision-making process for the approval of land use plans and their changes. However, this opportunity is not used very often by the public. In case of the extensive projects (and, of course, not exclusively of these projects) it is a necessity to plan and realize the participation of the public in an exceptional form already within the phase of the creation of the alternatives, e.g. in the form of round-tables, workshops, discussions, planning weekends, etc. During the whole project, the citizen should be considered an equal partner, and the opinions of the public should be reflected. The insufficient possibilities of the involvement in the negotiation of transport plans can even lead to efforts by the public to announce a referendum about a given construction (e.g. in the case of the planned transfer of the railway hub Brno). Similar initiatives represent a clear signal that citizens want to codecide on the form of the city in which they live.

\section{ECO-DRIVING}

"Eco-driving" or "environmental driving" is a method of driving which reduces the consumption of fuel, emissions of greenhouse gases, and the number of traffic accidents, and which brings benefits, not only to the environment, but mainly to drivers of motor vehicles. Driving the vehicle in accordance with the principles of "eco-driving" reduces the consumption of fuel by $10 \%$ or even more. Included in the fundamental elements of this method of driving, there are: maintaining a constant speed of the vehicle, the prediction of transport congestions and the finding of alternative "free" routes, gradual acceleration and braking, and regular checking of pressure in tyres.

The promotion of the principles of "eco-driving" in practice plans an international campaign which will be coordinated at a European level through the project ECODRIVEN. The goal of the campaign is to motivate at least 2.5 million drivers of passenger and freight vehicles in Europe to drive safer and in an energetically more efficient way, and reduce the emissions of $\mathrm{CO}_{2}$ by 0.5 million tons in 2010 .

\section{LAND USE PLANNING MEASURES}

The production of land use plans is part of very significant measures for the reduction of transport impact on the environment. The land use plan is a preventive tool which deals with the causes, not the consequences.

With the help of quality land use plans it is possible to achieve a reduction in the need for travelling and length of trips by car transport (through building of residential estates with good job opportunities), changes in modal split in favour of environmentally more friendly transport modes (e.g. building fast lanes for public transport), 
and, last but not least, the diversion of traffic from places where the population is directly exposed to emissions and noise from cars (planning of new roads, bypasses of cities and towns, etc.)

\section{OBSTACLES TO IMPLEMENTATION OF THE MEASURES}

\subsection{The acceptability of the measures for the public}

A lot of people use only passenger cars for all their transport needs. The measures which somehow restrict car traffic could be understood by this group of the public in a very negative way. It concerns mainly the charging of entrance to city centres, higher parking fees, environmental taxes on fuels, etc. In this respect the promotion of the measures is, mainly at the level of cities, very unpopular, and very hard to accept in terms of politics.

For example, in the field of air pollution, cities and regions are, according to the law, obliged to produce programs for the improvement of air quality, define the areas with a worsened quality of air, and design and implement the necessary remedial actions. The unpopularity of the measures which limit car traffic tend to be a cause for the shortfalls of these programs - the designed measures often stay only "on paper".

On the other hand, other measures tend to be welcomed by the public, e.g. cycle paths, new public transport services, or buses running on natural gas. Other measures could provoke different reactions: e.g. part of the public favourably reacts to the construction of new roads; the other part criticizes the construction.

\subsection{Other obstacles for implementation}

The measures designed in regional and city programmes are usually of cross-section character, and therefore their realization cannot be handled by simply one department of the corresponding authority. The issue concerns the departments of the environmental, transport, land use planning, and finance. The individual departments often have completely different opinions on the measures that should be implemented in a given locality (particularly the departments of transport and the environment). The solution to this issue is not simple. Nevertheless, the work groups composed of representatives of all concerned groups should be created for the implementation of the measures (programmes).

The work group should plan specific courses of action and their time schedule, choose the suppliers, monitor the progress of the implementation of the measures, etc. It is desirable that the producers of the programmes and general development plans containing the designed measures were represented in the given group.

In connection with the application of the reduction measures a question logically arises how financially demanding they are. However, not all of them are quantified in terms of costs. Specific actions (the building of infrastructure, purchase of vehicles, etc.), which differ very much financially concerning the used technology, material, type of vehicle, etc., could be quantified the best. The overview of the investment expenses on selected measures is shown in Table 7. 
Table 7: Investment expenses of selected measures (pricing level in 2006).

\begin{tabular}{|c|c|c|}
\hline \multicolumn{2}{|r|}{ Measure } & Price \\
\hline \multirow{9}{*}{$\begin{array}{l}\text { Support of the } \\
\text { environmentally } \\
\text { friendly transport } \\
\text { modes }\end{array}$} & $\begin{array}{l}\text { - modernization of rail corridors, } \\
\text { including the rail hubs }\end{array}$ & CZK $100 \mathrm{mil} . / \mathrm{km}$ \\
\hline & - low-floor tram & CZK 20-40 mil.. \\
\hline & - low-floor trolley-bus & CZK 8-12 mil. \\
\hline & - low-floor bus & CZK 4.5 mil. \\
\hline & - low-floor bus on $\mathrm{CNG}$ & CZK 6 mil. \\
\hline & - car park - area & $<\mathrm{CZK} 1$ thousand $/ \mathrm{m}^{2}$ \\
\hline & - car park - parking building & CZK 0.5 mil. / 1 stay \\
\hline & - storage of bicycles & $<\mathrm{CZK} 1000 / \mathrm{m}^{2}$ \\
\hline & - cycle path & CZK 2-4 thousand / $1 \mathrm{~m}$ \\
\hline \multicolumn{2}{|l|}{ Anti-noise barriers } & CZK $5-7.5$ thousand $/ \mathrm{m}^{2}$ \\
\hline \multirow{2}{*}{$\begin{array}{l}\text { Protection of wild } \\
\text { animals }\end{array}$} & - ecoduct & CZK 200 mil. \\
\hline & - fencing & CZK 60-120 thousand / $1 \mathrm{~km}$ \\
\hline
\end{tabular}

Source: Ministry of Transport

\section{SUMMARY}

Whether the negative effects of transport on health and the environment can be reduced depends on the success of the correct implementation of designed reduction measures, and for the elimination of these effects it is almost always necessary to adopt more measures. In this case there is a package of measures that are consistent with each other and their effectiveness is greater. As an example, it is possible to increase the positive impact of a new public transport service on the reduction of car transport together with building a Park \& Ride system in a suitable location on its route. From the draft of the measures to their implementation takes a long time, and, therefore, measures should always be designed by a team of professionals who can assess the effectiveness of different alternatives and subsequently design the optimum solution.

\section{ACKNOWLEDGEMENTS}

The research described in this article was established within research project of the Ministry of Transport of the Czech Republic under contact No. MD 04499457501 "Sustainable Transport - Chance for the Future".

\section{REFERENCES}

Adamec, V., Dostál, I., Jandová, V. et al., 2010. Study on transport trends from environmental viewpoints in the Czech Republic 2009. Brno: CDV, 136 p.

Anděl, P. et al., 2005. Hodnocení fragmentace krajiny dopravou. Praha: Agentura ochrany př́rody a krajiny, 99 p. ISBN 80-86064-92-1. (in Czech)

Bartoš, L., 2006. Navrhování komunikací pro cyklisty. Technické podmínky TP 179. Liberec: EDIP, s.r.o., 7 p. (in Czech) 
Bendtsen, H., Schmidt, B., 2006. Integrating noise in pavement management system for urban areas. Nordic Road and Transport Research, no. 3, pp. 26 - 27. ISSN 1101-5179.

Ďurčanská, D. et al., 2002. Posudzovanie vplyvov ciest a dialnic na životné prostredie. Žilina: Žilinská univerzita, EDIS, 257 pp. ISBN 80-8070-029-X. (in Slovak)

Haberl, J. et al., 2005. Integration of low-noise pavements with other noise abatement measures: SILVIA Project Report. Bruxelles: EC, 90 p.

Hensher, D.A., Button, K. J., 2003. Handbook of Transport and the Environment 4. London: Elsevier, 854 p. ISBN 978-0-08-044103-0.

Iuell, B., Bekker, H., Cuperus, R. et al., 2003. Wildlife and Traffic: An European Handbook for Identifying Conflicts and Designing Solutions. Utrecht (Netherlands): EC, COST 341, KNNV Publisher, 172 p. ISBN- 90-5011-186-6.

Lee-Gosselin, M., Doherty, S., 2005. Integrated land use and transport models: behavioural foundations. Amsterdam: Elsevier, 306 p. ISBN 0080446698. 